PROGNOSIS

\title{
Middle ear disease was associated with some behaviour problems at 5 and 10 years of age
}

\author{
Bennett KE, Haggard MP. Outcomes from middle ear disease. Arch Dis Child 1999 Jan;80:28-35.
}

\section{Question}

In young children, is middle ear disease associated with subsequent behaviour and cognitive problems? Middle ear disease was defined in 2 ways: parental reports of purulent (nonwax) ear discharge and suspected hearing loss.

\section{Design}

Cohort study with 10 years of follow up.

\section{Setting}

United Kingdom.

\section{Participants}

The original study included $>13000$ children born in the UK during the week of 5-11 April 1970. Children were assessed at birth and at 5, 10, 16, and 21 years of age. Approximately 9000 children were available for follow up at 10 years. Parental reports at 5 and 10 years indicated that $11.5 \%$ of the children had had ear discharge and 8.4\% had had suspected hearing difficulty.

\section{Assessment of prognostic factors}

Middle ear disease, sex, socioeconomic status (father's occupation, highest known qualification of either parent, type of accommodation, and neighbourhood), and maternal malaise (depression, neuroticism, and feeling miserable) at 5 and 10 years.

\section{Main outcome measures}

Using standardised behaviour rating scales, parents reported antisocial, neurotic, hyperactive, and poor conduct behaviour at
5 years. Parents and teachers reported antisocial and neurotic behaviour, inattentiveness, and clumsiness at 10 years. Teachers also reported speech articulation.

\section{Main results}

At 5 years, parent reported antisocial, neurotic, and hyperactive behaviour were associated with ear discharge and hearing difficulty (table). Poor conduct was associated with hearing difficulty. At 10 years, parent reported neurotic and hyperactive behaviour and clumsiness were associated with both ear discharge and hearing difficulty, and antisocial behaviour was associated with ear discharge. At 10 years, teacher reported antisocial behaviour was associated with ear discharge and hearing difficulty, and clumsiness was associated with hearing difficulty. Speech articulation was associated with ear discharge $(p=0.048)$ and hearing difficulty $(\mathrm{p}=0.004)$. Children with hearing difficulties had lower verbal $(\mathrm{p}<0.05)$ and non-verbal $(\mathrm{p}=0.01)$ test scores at 5 years. At 10 years, children with ear discharge had lower language skills scores $(\mathrm{p}=0.01)$.

\section{Conclusion}

Children with previous middle ear disease had subsequent parent and teacher reported behaviour and cognition problems.

Source of funding: in part, the Hearing Research Trust.

For correspondence: Dr K E Bennett, MRC Institute of Hearing Research, University Park, Nottingham NG7 2RD, UK. Fax +44 (0)1559518503.

Odds ratios (and 95\% confidence intervals) for the association of middle ear disease with behaviour outcomes in young children (adjusted for maternal malaise, sex, and socioeconomic status)

\begin{tabular}{|c|c|c|c|c|c|c|}
\hline Middle ear disease & Report & Time & Antisocial behaviour & Neurotic behaviour & Hyperactivity & Poor conduct \\
\hline Ear discharge & Parent & $5 y$ & 1.27 (1.07 to 1.52$)$ & $1.27(1.07$ to 1.51$)$ & 1.29 (1.09 to 1.52$)$ & $1.19(1.0 \text { to } 1.42)^{*}$ \\
\hline Hearing difficulty & Parent & $5 y$ & $1.44(1.18$ to 1.76$)$ & $1.52(1.26$ to 1.85$)$ & $1.56(1.29$ to 1.89$)$ & $\begin{array}{l}1.37 \text { ( } 1.12 \text { to } 1.67) \\
\text { Clumsiness }\end{array}$ \\
\hline Ear discharge & Parent & $10 \mathrm{y}$ & $1.26(1.05$ to 1.52$)$ & $1.26(1.05$ to 1.52$)$ & 1.37 (1.15 to 1.64$)$ & $1.29(1.08$ to 1.55$)$ \\
\hline Hearing difficulty & Parent & $10 \mathrm{y}$ & $1.10(0.87 \text { to } 1.38)^{*}$ & $1.40(1.14$ to 1.72$)$ & $\begin{array}{l}1.76(1.45 \text { to } 2.14) \\
\text { Inattention }\end{array}$ & $1.36(1.10$ to 1.67$)$ \\
\hline Ear discharge & Teacher & $10 \mathrm{y}$ & $1.42(1.17$ to 1.73$)$ & $1.10(0.89 \text { to } 1.35)^{*}$ & $1.17(0.95 \text { to } 1.44)^{*}$ & $1.10(0.90 \text { to } 1.36)^{*}$ \\
\hline Hearing difficulty & Teacher & $10 \mathrm{y}$ & $1.38(1.10$ to 1.73$)$ & $1.25(0.99 \text { to } 1.58)^{*}$ & $1.07(0.83 \text { to } 1.37)^{*}$ & $1.31(1.04$ to 1.64$)$ \\
\hline
\end{tabular}

*Not significant.

\section{Commentary}

Bennett and Haggard analysed data from the 1970 British Birth Cohort, a multipurpose longitudinal study designed to investigate educational, physical, and social development. The study has several strengths. The sample size is much larger than other studies that have examined the behavioural and developmental effects of middle ear disease. ${ }^{1-3}$ Outcomes were measured using standardised behaviour scales with input from parents and teachers. Odds ratios were adjusted for confounding factors. The study permits evaluation of the long term effects of middle ear disease by including 10 year assessments.

The study also has limitations, however. Firstly, the authors did not consider alter- native explanations for hearing difficulty, such as neurological impairment. Secondly, middle ear disease was reported by parents, and their recall may not have been accurate. Thirdly, although the sample size was large enough to detect differences between groups, some of the differences may not be clinically significant. For example, although deficits in speech articulation for children with ear discharge and hearing difficulty are statistically significant, the deficits are relatively small. The largest effects were observed for behaviour problems and language test data at age 5 .

The study highlights the importance of treating acute otitis media. ${ }^{4}$ In addition, the value of early recognition of behavioural and cognitive problems cannot be underestimated, because early recognition can lead to early treatment, which may help to alleviate long term problems.

Linda Yvonne Perry, RN, RSCN Clinical Nurse Manager

The National Centre for Children and Young People with Epilepsy and Other Special Needs St Piers, Lingfield, Surrey, UK

1 Silva P, Kirkland C, Simpson A, et al. J Learn Disabil 1984;15:417-21.

2 Schilder AG, Van Manen JG, Zielhuis GA, et al. Clin Otolaryngol 1993;18:234-41.

3 Teele DW, Klein JO, Rosner BA. Pediatrics 1984.74.089-7.

4 Glasziou PP, Hayem M, Del Mar CB. Antibiotics versus placebo for acute otitis media in children (Cochrane Review. Latest version 26 August 1996). In: Cochrane Library. Oxford: Update Software. 